\title{
Article
}

\section{Experimental and computational investigation of co production and dispersion in an automotive repair shop}

Asimakopoulou, Eleni, Kolaitis, Dionysios and Founti, Maria Available at http://clok.uclan.ac.uk/31941/

Asimakopoulou, Eleni ORCID: 0000-0001-5644-1372, Kolaitis, Dionysios and Founti, Maria (2013) Experimental and computational investigation of co production and dispersion in an automotive repair shop. Indoor and Built Environment, 22 (5). pp. 750-765. ISSN 1420-326X

It is advisable to refer to the publisher's version if you intend to cite from the work. http://dx.doi.org/10.1177/1420326x12458300

For more information about UCLan's research in this area go to http://www.uclan.ac.uk/researchgroups/ and search for <name of research Group>.

For information about Research generally at UCLan please go to http://www.uclan.ac.uk/research/

All outputs in CLoK are protected by Intellectual Property Rights law, including Copyright law. Copyright, IPR and Moral Rights for the works on this site are retained by the individual authors and/or other copyright owners. Terms and conditions for use of this material are defined in the policies page.

\section{CLoK}

Central Lancashire online Knowledge www.clok.uclan.ac.uk

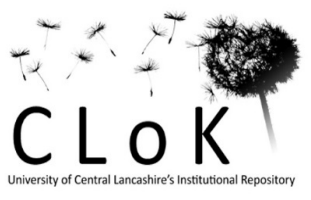


All content following this page was uploaded by Dionysios I. Kolaitis on 11 September 2015 . The user has requested enhancement of the downloaded file. 


\title{
Experimental and Computational Investigation of CO Production and Dispersion in an Automotive Repair Shop
}

\author{
Eleni K. Asimakopoulou, Dionysios I. Kolaitis* and Maria A. Founti \\ Laboratory of Heterogeneous Mixtures and Combustion Systems, Thermal Engineering Section, \\ School of Mechanical Engineering, National Technical University of Athens, \\ 9, Heroon Polytechniou St., 15670 Zografos, Greece \\ *Corresponding author, e-mail: dkol@central.ntua.gr , Tel.: +30-210-7724002, Fax: +30-210-7723527
}

\begin{abstract}
Carbon monoxide (CO), a highly toxic gas, is produced during the incomplete combustion of carbon-based fuels. In indoor environments, high $\mathrm{CO}$ concentrations constitute a serious occupational health hazard; this is especially true in the case of Automotive Repair Shop (ARS) employees who are exposed on a daily basis to vehicle exhaust streams. The present study focuses on the experimental investigation and numerical simulation of CO production and dispersion inside an ARS facility. Detailed measurements of CO concentration, vehicle traffic and ventilation system velocities are performed; the obtained data are appropriately formulated to provide quantitative information for modelling purposes. A detailed Computational Fluid Dynamics simulation of the developing transient flow-field is performed. The numerical results are validated using the experimental data; an overall good qualitative and quantitative agreement is achieved. Aiming to improve the energy efficiency of the mechanical ventilation system, three alternative scenarios are investigated; it is shown that the utilization of a dynamic ventilation system may result in significant energy consumption benefits, while, at the same time, $\mathrm{CO}$ concentrations remain below the values suggested by current occupational health legislation. The obtained results may be utilized to assist the design of mechanical ventilation systems for ARS facilities.
\end{abstract}

\section{Keywords}

CO, dispersion, automotive repair shop, CFD, indoor air quality, occupational health

\section{Introduction}

Carbon monoxide is a colourless, odourless, tasteless, non-irritating but highly toxic gas, which is produced by the incomplete combustion of any carbon-based fuel [1]. The effects of $\mathrm{CO}$ inhalation can be toxic or even lethal; $\mathrm{CO}$ is preferentially bound with haemoglobin $(\mathrm{Hb})$ molecules in the blood stream, forming carboxy-haemoglobin $(\mathrm{COHb})$ that eventually leads to the limitation of oxygen delivery to the tissues of the human body [2]. The dominant parameters affecting $\mathrm{COHb}$ concentration in the blood are exposure time and $\mathrm{CO}$ concentration in the inhaled atmosphere; $\mathrm{COHb}$ tolerance also depends on age, sex and the pre-existing physical condition of a person [3].

$\mathrm{CO}$ accumulation, especially in inadequately ventilated spaces, constitutes a serious health hazard for the occupants. CO intoxication may occur in a wide variety of settings; CO acute poisonings are mainly owed to uncontrollable fires and exhaust emissions from vehicle Internal Combustion Engine (ICE) [4]. CO is commonly found in the exhaust stream of spark ignition ICE due to a variety of thermo-chemical processes, such as incomplete oxidation due to rapid temperature decrease in the expansion and exhaust phases, cold surface quenching and partial oxidation of the unburned fuel [1].

Research activities regarding ICE exhaust CO emissions in indoor spaces have been mainly focused on enclosed automotive parking garage facilities. Extensive measurements of flow-, 
thermal- and concentration-fields in a large underground parking garage [5] have been used to derive correlations between the mean $\mathrm{CO}$ concentration and the mean air velocity, the turbulence intensity and the number of vehicles entering or leaving the parking, aiming to provide ventilation system design data. An experimental study investigating indoor air quality conditions in multi-level enclosed parking facilities [6], has provided $\mathrm{CO}$ concentrations at six different facilities. The obtained data were compared to occupational health and safety recommended values; $\mathrm{CO}$ concentration levels were found to vary significantly depending on site, time and day of measurement. Measurements of traffic volume, hourly engine operation time, parking occupancy level, $\mathrm{CO}$ and temperature levels, obtained in a medium sized commercial underground parking garage were used to develop correlations of hourly average $\mathrm{CO}$ concentrations with the engine operating time fraction and the effect of the ventilation system [7]. A large variety of air pollutants, such as $\mathrm{CO}$ and Volatile Organic Compounds (VOCs), have been measured, using time-resolved methods, in an urban parking garage [8]; the influence of vehicle activity and type on the pollutant levels has been assessed.

Employees of Automotive Repair Shops (ARS) may be exposed to high ICE exhaust CO emissions for prolonged time periods, similarly to the conditions of enclosed automotive parking garage facilities. A significant risk of high $\mathrm{COHb}$ blood concentrations is known to exist for this group [9]. However, scarce reports are available in the open literature focusing on the CO related health risks for ARS employees. An experimental investigation of CO concentration levels in three ARS facilities of varying work environment size has highlighted the main affecting parameters, i.e. type of ventilation system, volume and type of repairs and employee work habits [10]. In this case, the measured 8-hour time-weighted average $\mathrm{CO}$ concentration levels, in warm weather conditions, were found to range from $3.3 \mathrm{ppm}$ to $21.6 \mathrm{ppm}$.

\section{Guidelines for Indoor CO Concentration Levels}

Since even low CO concentrations may cause a variety of adverse health effects, such as headache, nausea, dizziness, weariness, decrease in myocardial oxygen consumption and increase in coronary flow and heart rate $[6,11]$, a variety of occupational safety guidelines, relevant to the risks associated with $\mathrm{CO}$ concentration levels in indoor environments, have been developed. The respective Indoor Air Quality (IAQ) guidelines are commonly expressed in the form of maximum allowable $\mathrm{CO}$ concentration levels. A selection of characteristic Time Weighted Average (TWA) values, based on IAQ CO concentration guidelines for a typical 8-hour working day from representative international organizations and legal bodies, is given in Table 1. As expected, the suggested IAQ CO concentration levels decrease with increasing weighting time period. However, there are significant discrepancies among the suggested values of the various legal bodies.

General IAQ guidelines for ARS facilities suggest the use of dedicated mechanical ventilation systems capable of maintaining $\mathrm{CO}$ concentration levels constantly below the maximum allowable concentration values that are explicitly described in local jurisdiction health safety regulations, codes or standards. The mechanical ventilation system may operate either continuously or intermittently; in the latter case ("dynamic ventilation" system), gas detection systems to monitor and control CO concentrations in the ventilated space are needed. Installation of CO sensors is not common in ARS facilities; however, they are frequently used in automotive parking facilities. 
Table 1 . Indoor air quality guideline values for time weighted average CO concentrations.

\begin{tabular}{|c|c|c|c|c|}
\hline \multirow{2}{*}{ Legal Body } & \multicolumn{3}{|c|}{ TWA CO Concentration } & \multirow[b]{2}{*}{ Reference } \\
\hline & $\begin{array}{c}\text { Weighting } \\
\text { Time }\end{array}$ & ppm & $\mathrm{mg} / \mathrm{m}^{3}$ & \\
\hline \multirow{4}{*}{$\begin{array}{c}\text { World Health } \\
\text { Organization (WHO) }\end{array}$} & $15 \min$ & 90 & 100 & \multirow{4}{*}[12]{} \\
\hline & $30 \mathrm{~min}$ & 50 & 60 & \\
\hline & $1 \mathrm{hr}$ & 26 & 30 & \\
\hline & $8 \mathrm{hr}$ & 9 & 10 & \\
\hline $\begin{array}{c}\text { National Institute of } \\
\text { Safety and Health (NIOSH) }\end{array}$ & $8 \mathrm{hr}$ & 35 & 40 & [13] \\
\hline $\begin{array}{c}\text { American Conference of } \\
\text { Government Industrial } \\
\text { Hygienists (ACGIH) }\end{array}$ & $8 \mathrm{hr}$ & 25 & 29 & {$[14]$} \\
\hline European Community (EC) & $15 \mathrm{~min}$ & 50 & 55 & {$[15]$} \\
\hline
\end{tabular}

\section{Numerical Modelling of CO Dispersion in Indoor Environments}

During the last few years, there is an increasing utilization of numerical modelling tools for the simulation of indoor pollutant dispersion and air movement in a variety of applications related to occupational health. In this context, the most advanced numerical tools available today are Computational Fluid Dynamic (CFD) codes, which are capable of accurately predicting, among others, the velocity and concentration fields inside an enclosed or semienclosed space. CFD simulation studies can be useful alternatives for analyzing, designing, optimizing and validating the operation of ventilation systems, whenever conventional approaches requiring physical testing may be too expensive and time-consuming. A large variety of in-house developed and commercially available CFD codes, such as PHOENICS [16], FLUENT [17], CFX [18], are currently available to investigate the impact of ventilation conditions on the IAQ of an enclosed space.

There are few CFD modelling studies available, focusing on the effects of indoor CO production and dispersion due to ICE exhaust emissions; in these studies, underground parking facilities are usually investigated. To the authors' knowledge, no CFD studies investigating $\mathrm{CO}$ dispersion in ARS facilities are available, despite the potential significant occupational health hazards associated with this type of working environment. The $\mathrm{CO}$ concentration levels in an enclosed or semi-enclosed space are greatly affected by three main parameters, namely traffic density, air distribution and mechanical ventilation rate [19]; these factors are investigated in the majority of the available CFD simulations. A CFD study of different ventilation systems in an underground parking facility revealed that improper mixing in the ventilation system could result in higher $\mathrm{CO}$ concentrations at selected regions, thus highlighting the importance of proper ventilation system design [20]. Another CFD simulation of bus pollutant emissions in a public transport interchange station revealed that a ceiling based ventilation system may significantly improve the attained IAQ conditions [18].

The scope of this work is to systematically examine the characteristics of CO dispersion inside an ARS facility; towards this end, both experimental investigation and CFD simulation methodologies are used. Detailed measurements of CO concentration, vehicle traffic and ventilation system velocities are used to provide quantitative information for modelling purposes. At first, predictions are validated against the obtained experimental data for the 
investigated ARS facility. Furthermore, a variety of alternative mechanical ventilation scenarios is investigated, aiming to reduce the corresponding energy consumption, while maintaining compliance with $\mathrm{CO}$ guidelines suggested by the occupational health legislation. The parametric study is intended to assist the design procedure of mechanical ventilation systems for ARS facilities.

\section{Experimental Investigation}

The experimental investigation has been performed in a medium-scale ARS operating in Greece. The general layout of the facility and the corresponding main dimensions are depicted in Figure 1. The considered ARS can accommodate up to 25 vehicles providing full-service automotive repair facilities. It has a total effective area of $1261.8 \mathrm{~m}^{2}$, including office spaces $\left(91.2 \mathrm{~m}^{2}\right)$, a lobby $\left(45 \mathrm{~m}^{2}\right)$, for client waiting (up to $2 \mathrm{hr}$ ) and a warehouse $\left(145.6 \mathrm{~m}^{2}\right)$. The facility has two entrances; the main entrance (A1), measuring $2.85 \mathrm{~m} \times 3 \mathrm{~m}$, is positioned in the southern side, whereas the secondary entrance (A2), measuring $2 \mathrm{~m} \times 3$ $\mathrm{m}$, is located in the western side. Both entrances, $\mathrm{A} 1$ and $\mathrm{A} 2$, remain totally open during a typical working day, thus allowing "fresh" air to freely enter the facility. Vehicles generally enter the ARS through the main entrance (A1); they are driven to a workplace location where they stay for a period of time and they exit the facility through either the main (A1) or the secondary entrance (A2). A staircase leading to the first floor of the building is located near the south-east corner of the lobby; as a result, there is a $2 \mathrm{~m} \times 2 \mathrm{~m}$ opening (A3) placed on the ceiling of the lobby.

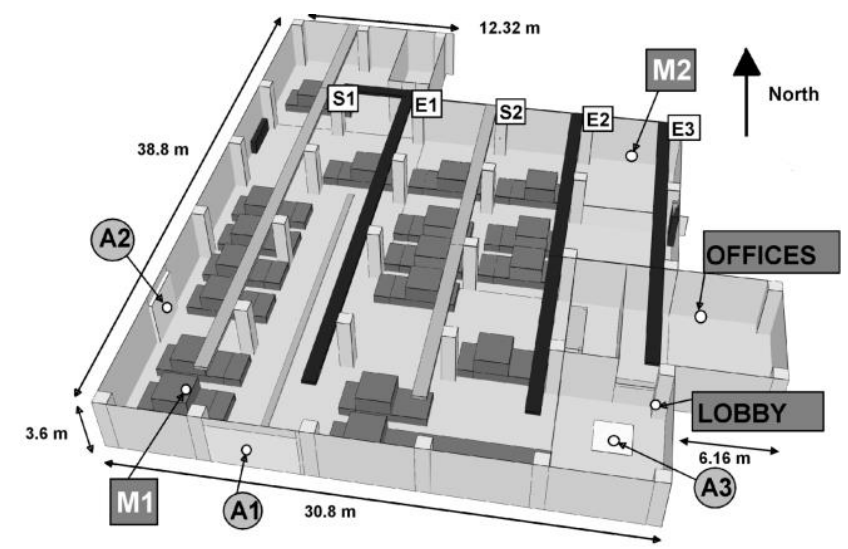

Figure 1. General layout of the investigated ARS facility.

The ventilation system installed in the investigated ARS is a conventional "balanced" constant pressure mechanical ventilation system. The ventilation system consists of two separate sub-systems; the "supply" sub-system through which "fresh" ambient air is introduced to the facility (light grey coloured ducts in Figure 1) and the "extraction" subsystem that removes the gaseous mixture from the facility (black coloured ducts in Figure 1). The supply sub-system consists of two branches ( $\mathrm{S} 1$ and $\mathrm{S} 2$ ), whereas the extraction subsystem consists of three branches (E1, E2 and E3); all branches are located at a height of 3.5 $\mathrm{m}$ with approximately $5.0 \mathrm{~m}$ spacing between them. All ventilation branches have a common orthogonal cross section, measuring $0.8 \mathrm{~m}$ (width) x $0.2 \mathrm{~m}$ (height); branches E1, S2 and E2 are $28.2 \mathrm{~m}$ long, whereas the length of branches S1 and E3 is $36.2 \mathrm{~m}$ and $22.6 \mathrm{~m}$, respectively. The short "elbow" part of branch E1 exhibits no exhaust vents. In total, "fresh" outdoor air is introduced through 20 vents in the supply branches, whereas 28 vents in the extraction branches are used to remove the "impure" air at a specified flow rate. All vents have an orthogonal cross-section, measuring $0.4 \mathrm{~m}$ (width) x $0.2 \mathrm{~m}$ (height), and are symmetrically positioned on both sides of the ducts (Figure 2). The air ventilation 
volumetric flow rate corresponds to 8 Air Changes per Hour (ACH), in accordance to the Greek legislation [21] governing the operation of ARS facilities.

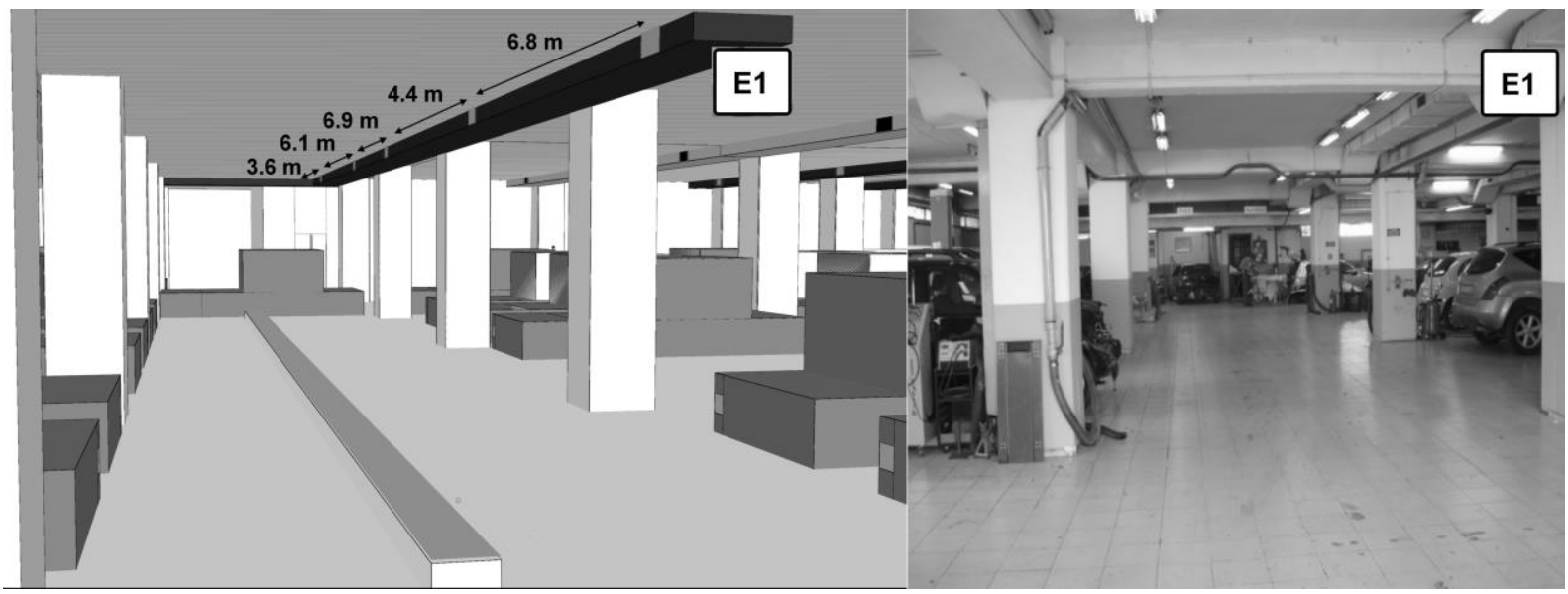

Figure 2. Layout of the western orientation rectangular vents in the E1 branch and location of the "artificial" CO linear mass source (left) and respective photograph (right).

\section{Measurements of CO Concentration}

Two portable electrochemical cell gas analyzer devices were employed to obtain continuous $\mathrm{CO}$ concentration measurements. Both the utilized gas analyzer devices (MRU Delta 2000CD, Madur GA-40 plus) exhibited similar technical characteristics; CO measuring capacity ranging from $0 \mathrm{ppm}$ to $4000 \mathrm{ppm}$, total accuracy of $\pm 5 \%$ and measurement resolution of $1 \mathrm{ppm}$. Two characteristic monitoring positions, shown in Figure 1, have been selected, corresponding to typical workplace conditions. The first monitoring position (M1) is located at the south-west corner of the ARS facility (at a distance of $0.7 \mathrm{~m}$ from the west wall and $2.4 \mathrm{~m}$ from the south wall); M1 lies between the two open entrances (c.f. Figure 1), corresponding to a well-ventilated (mechanically and naturally) area. The second monitoring position (M2) is located near the north-east corner (at a distance of $1.5 \mathrm{~m}$ from the east wall and $5.2 \mathrm{~m}$ from the north wall), far away from all openings of the facility; engine exhaust gases are expected to accumulate in this region. The gas analyzer measuring probes have been located at a height of $1.6 \mathrm{~m}$ above the floor, which corresponds to the breathing zone of an average person; the sampling period was $20 \mathrm{~s}$ for position M1 and $10 \mathrm{~s}$ for position M2. Measurements have been obtained over several typical working days (from 09:00 to 16:00).

The temporal evolution of 15 min TWA CO concentration levels, measured during a typical working day, is depicted in Figure 3. As expected, mean CO concentrations in position M1, which was located near the open entrances, were generally lower than the respective values obtained in position M2. It is evident that in both cases the measured values are significantly lower than the 15 min TWA limiting values, as suggested by WHO (90 ppm) and the European legislation $(50 \mathrm{ppm})$. However, the measured $15 \mathrm{~min}$ TWA CO concentrations in position M2 could occasionally exceed the $8 \mathrm{hr}$ TWA CO levels that are suggested by WHO (9 ppm). 


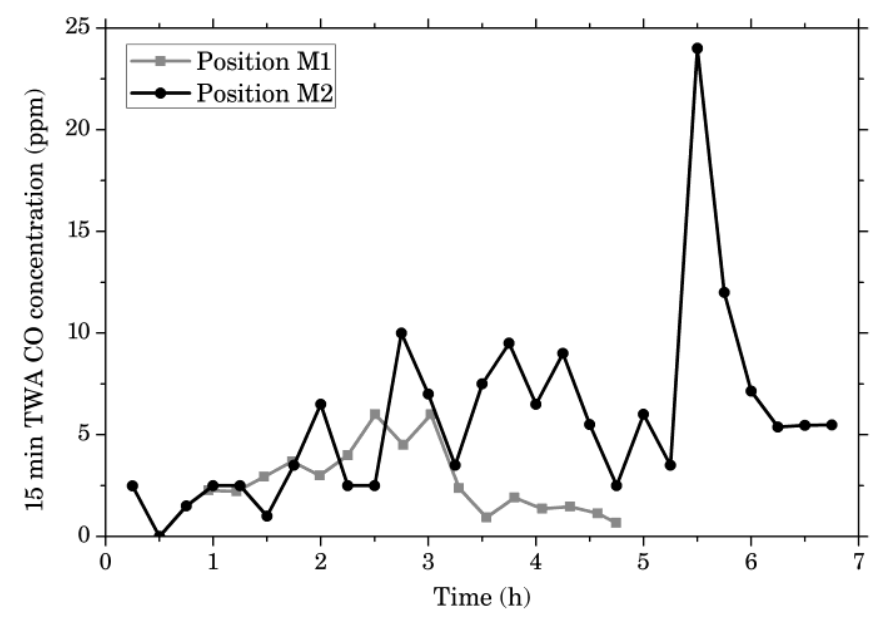

Figure 3. Measured time evolution of 15 min TWA CO concentrations for a typical working day.

\section{Measurements of Indoor Vehicle Traffic}

Aiming to correlate the measured CO concentrations with the actual ARS working load, a range of additional parameters was recorded. The approximate position of the vehicles in the ARS facility, the direction of vehicle movement and the actual vehicle engine operating time were recorded, for a typical working day, at $30 \mathrm{~s}$ time-steps. Due to difficulties in accurately measuring the engine operating time and the exact position of the moving vehicles, a simplifying assumption was used. Four characteristic positions along the main entrance passageway of the ARS were defined; averaging of the recorded vehicle engine operating time, by taking into account vehicle movement among these positions, resulted in the formulation of an overall "equivalent" vehicle engine operating time graph, pertaining to the entire ARS facility (Figure 4). Non integer values are owed to spatial and temporal weighted averaging of the data obtained in the four monitoring positions using a $30 \mathrm{~s}$ "recording interval". The obtained results correspond to a typical medium-sized ARS; as a result, they can be used for occupational safety engineering calculations, as well as to provide reliable boundary conditions for detailed numerical simulations (c.f. Section 3.2).

\section{Measurements of Gas Velocities}

The main (A1) and secondary (A2) entrances of the ARS facility remain fully open throughout the entire typical working day, thus providing an additional source of "natural" ventilation. A TESTO 435 digital airflow meter, with an $8 \mathrm{~mm}$ hot wire probe, has been used to measure the "fresh" air flow through the main and secondary entrances. The velocity measurements have been recorded every $1 \mathrm{~s}$ for a period of $20 \mathrm{~min}$ in three different height levels; the respective time averaged values are presented in Table 2 . Positive values signify "inflow" conditions, whereas negative values correspond to "outflow" conditions. It is evident that the combination of the prevailing local wind conditions and the building orientation of the ARS facility, had resulted in a continuous supply of "fresh" ambient air through the main entrance (A1) and a corresponding continuous "impure" air extraction through the secondary entrance (A2); thus, a constant "natural" ventilation flow pattern was established.

Airflow velocities at the rectangular vents of the supply and extraction branches of the ventilation system were also measured using the TESTO 435 digital airflow meter. The respective mean velocity values, averaged over the area of each vent, are presented in Table 3. The values reported in the first column corresponded to the mean distance of each vent from the northern tip of the respective branch (c.f. Figure 2). In some cases, marked with 
$\mathrm{N} / \mathrm{A}$, the vents were set to the "closed" position and no measurements could be obtained. It is evident that the ventilation system exhibited significant differences in vent exit velocities, both along the length (north-south axis), as well as across the width (east-west axis) of the various branches.

Table 2. Time averaged air flow velocities at the ARS main and secondary entrance.

\begin{tabular}{ccccccc}
\hline Opening & \multicolumn{3}{c}{ Main Entrance (A1) } & \multicolumn{3}{c}{ Secondary Entrance (A2) } \\
\hline Height $(\mathrm{m})$ & 0.7 & 1.35 & 2.1 & 0.7 & 1.4 & 2.0 \\
Average velocity $(\mathrm{m} / \mathrm{s})$ & +0.39 & +0.24 & +0.21 & -0.43 & -0.49 & -0.33 \\
\hline
\end{tabular}

Table 3. Measured average vent velocities at the supply and extraction branches of the ventilation system.

\begin{tabular}{|c|c|c|c|c|c|c|c|c|c|c|}
\hline \multirow{3}{*}{$\begin{array}{c}\text { Branch } \\
\text { Orientation }\end{array}$} & \multicolumn{10}{|c|}{ Average Velocity $(\mathrm{m} / \mathrm{s})$} \\
\hline & \multicolumn{2}{|c|}{ S1 } & \multicolumn{2}{|c|}{ S2 } & \multicolumn{2}{|c|}{ E1 } & \multicolumn{2}{|c|}{ E2 } & \multicolumn{2}{|c|}{ E3 } \\
\hline & W & E & W & E & W & $\mathrm{E}$ & W & E & W & $\mathrm{E}$ \\
\hline $3.6 \mathrm{~m}$ & $\mathrm{~N} / \mathrm{A}$ & $\mathrm{N} / \mathrm{A}$ & $\begin{array}{c}+ \\
1.5\end{array}$ & $\mathrm{~N} / \mathrm{A}$ & -4.9 & -1.4 & -3.5 & $\mathrm{~N} / \mathrm{A}$ & $\mathrm{N} / \mathrm{A}$ & $\mathrm{N} / \mathrm{A}$ \\
\hline $9.7 \mathrm{~m}$ & $\begin{array}{c}+ \\
1.0\end{array}$ & $\begin{array}{c}+ \\
1.0\end{array}$ & $\begin{array}{c}+ \\
0.9\end{array}$ & N/A & -2.8 & N/A & N/A & $\mathrm{N} / \mathrm{A}$ & $\mathrm{N} / \mathrm{A}$ & N/A \\
\hline $16.6 \mathrm{~m}$ & $\begin{array}{c}+ \\
1.3\end{array}$ & $\mathrm{~N} / \mathrm{A}$ & $\begin{array}{c}+ \\
1.5\end{array}$ & $\mathrm{~N} / \mathrm{A}$ & -4.4 & N/A & -5.6 & $\mathrm{~N} / \mathrm{A}$ & -4.1 & -2.0 \\
\hline $21.0 \mathrm{~m}$ & $\begin{array}{c}+ \\
1.2\end{array}$ & $\begin{array}{c}+ \\
0.8\end{array}$ & $\begin{array}{c}+ \\
1.4\end{array}$ & $\begin{array}{c}+ \\
1.4\end{array}$ & -3.7 & -6.7 & N/A & $\mathrm{N} / \mathrm{A}$ & -1.0 & $\mathrm{~N} / \mathrm{A}$ \\
\hline $27.8 \mathrm{~m}$ & $\begin{array}{c}+ \\
2.3\end{array}$ & $\begin{array}{c}+ \\
3.6\end{array}$ & $\begin{array}{c}+ \\
3.3\end{array}$ & $\begin{array}{c}+ \\
3.1\end{array}$ & -4.9 & -1.9 & -3.2 & -5.6 & $\mathrm{~N} / \mathrm{A}$ & N/A \\
\hline
\end{tabular}

\section{Numerical Simulation}

The Fire Dynamics Simulator (FDS), version 5.5.3, developed by the National Institute of Standards and Technology [22], has been employed for the simulation of CO dispersion in the ARS facility. The FDS code has been used in a large variety of fire-related applications, such as fundamental studies of fire dynamics and combustion, fire protection engineering, fire investigation, fire scene reconstruction etc. In this context, the FDS code has been validated regarding its capabilities in predicting the dispersion of gas species in indoor environments both in the case of fire conditions [23] and in the case of non-combusting environments [24]; it has also been used for IAQ applications [25].

The equations of mass, momentum and energy conservation are solved in the FDS code by assuming low Mach flow conditions; the solution is updated in time on a three-dimensional, rectilinear grid. The core algorithm utilizes an explicit predictor-corrector scheme that is second order accurate in space and time. The time step is dynamically adjusted so that the CFL (Courant-Friedrichs-Lewy) condition can be satisfied; in the simulations reported in this study, the mean numerical time-step varied from $8 \mathrm{~ms}$ to $78 \mathrm{~ms}$. Turbulent phenomena re taken into account by using the Large Eddy Simulation (LES) approach. Detailed information regarding the form of the solved equations and the utilized numerical schemes are provided in the technical reference guide of the FDS code [22]. 


\section{Initial and Boundary Conditions}

The computational grid used in the simulations $(39.6 \mathrm{~m} \times 38.0 \mathrm{~m} \times 3.6 \mathrm{~m})$ was slightly larger than the physical space of the investigated ARS facility $(38.8 \mathrm{~m} \times 36.96 \mathrm{~m} \times 3.6 \mathrm{~m})$ (c.f. Figure 1). The Cartesian numerical grid used in the simulations consisted of 488,700 cubic $(0.2 \mathrm{~m}$ side) cells. 18 "solid" bodies were included in the computational domain, representing the average number of the vehicles that are typically parked inside the ARS; each vehicle occupied a volume of $10 \mathrm{~m}^{3}$ (dark grey bodies in Figure 1). Gas velocities and $\mathrm{CO}$ concentrations were assumed to be zero when the simulation was started.

"Fresh" air was supplied to the ARS through the main entrance (A1) and "impure" air was removed from the computational domain through the secondary entrance (A2); each entrance was vertically divided in three areas and the corresponding measured velocity values were used throughout the simulation (c.f. Table 2). The "fresh" air introduced to the domain was considered to be free from CO. The "impure" air was allowed to exit the computational domain through the opening at the ceiling of the lobby (A3). The measured mean velocity values in all the "operating" ventilation vents (14 inlet vents in the "fresh" air supply sub-system and 15 outlet vents in the "impure" air extraction sub-system) were taken into account (c.f. Table 3) in order to effectively simulate the operation of the ventilation system.

\section{Modelling of the CO Emission Source}

Appropriate modelling of $\mathrm{CO}$ production is the single most important parameter for the accurate simulation of indoor $\mathrm{CO}$ dispersion; despite the accurate simulation of the developing flow-field, the inadequate description of the CO source could result in highly inaccurate predictions. In order to effectively simulate the CO source, the quantity and location of $\mathrm{CO}$ emissions must be accurately described.

Table 4. "Hot" and "cold" start ICE exhaust CO emissions in parking garages.

\begin{tabular}{ccc}
\hline Season & $\begin{array}{c}\text { "Hot Start" } \\
\text { (gr/min) }\end{array}$ & $\begin{array}{c}\text { "Cold Start" } \\
\text { (gr/min) }\end{array}$ \\
\hline Summer $\left(32.2^{\circ} \mathrm{C}\right)$ & 1.89 & 3.66 \\
Winter $\left(-1^{\circ} \mathrm{C}\right)$ & 3.38 & 18.96 \\
Simulation $\left(18^{\circ} \mathrm{C}\right)$ & & 10.41 \\
\hline
\end{tabular}

In general, the flow rate and composition of vehicle ICE exhaust emissions strongly depend on the operational mode of the engine. For light duty vehicles, "cold start", "hot start" and "hot stabilized" operational modes are typically considered [26]. The "start" modes correspond to the first few minutes after turning on the vehicle's engine; in this case, the engine is at full choke and operates with a rich mixture, resulting in higher CO emissions. If the engine is started after a long period of inactivity, "cold start" conditions are considered; in contrast, if the engine is restarted shortly after being shutoff, the operational mode is characterized as "hot start". The "cold start" conditions result in higher exhaust emissions as compared to the "hot start" conditions, since the catalytic converters are generally operating far from their optimal temperature. The "hot stabilized" mode occurs when the engine is running for a substantial time after the "start" mode; in general, emission rates in this case are lower than in the "start" mode. Standard vehicle maintenance operations performed in typical ARS facilities include engine inspection, diagnostics and testing, as well as exhaust emission measurements. In these cases, vehicle engines are generally switched on for short periods of time; as a result, CO emissions corresponding to "cold 
start" conditions were utilized in the numerical simulations. Standard CO emissions for "hot start" and "cold start" operational modes, according to the Handbook of the American Society of Heating, Refrigerating and Air-Conditioning Engineers (ASHRAE) [26] are given in Table 4.

In the investigated ARS facility, it was observed that the vehicles' engines were operating during two main phases; vehicles entering or leaving the ARS and vehicles undergoing exhaust emission measurement. In the latter case, the vehicle's engine remained operational for a period of 2-3 min; as a result, the use of the "cold start" operational mode was justified to estimate $\mathrm{CO}$ emissions. Measurements were obtained during spring, with a mean ambient temperature equal to $18^{\circ} \mathrm{C}$. A linear interpolation of the $\mathrm{CO}$ emission values, suggested by ASHRAE, was undertaken to match the weather conditions; the obtained value for "cold start" conditions was $10.41 \mathrm{~g} / \mathrm{min}$.

In CFD simulations of ICE exhaust emissions dispersion, CO production is commonly described either as a "steady state" [18] or as a "transient" (time dependent) CO mass source [27]; the respective values are usually selected utilizing information regarding the operational mode of the ICE engines. The location of the CO mass source is an important simulation parameter, since the emitting vehicles are usually moving inside the simulated physical space. The most common approach assumes a "global" CO mass term, extending to the entire area of the simulated physical space [20,27]. In a recent study focusing on the CFD simulation of ICE exhaust emissions in a public transport interchange, an "artificial" line CO source was utilized [18].

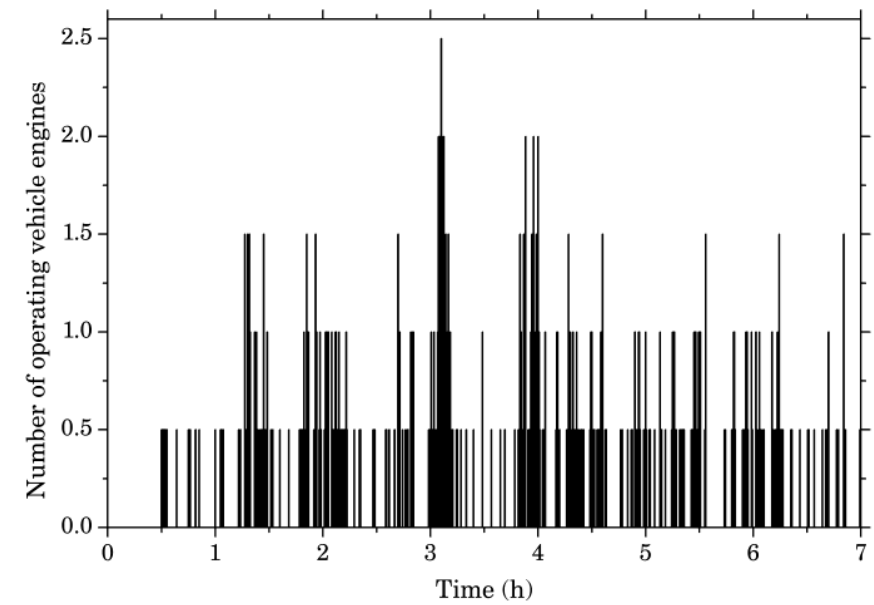

Figure 4. Number of operating vehicle engines versus time for a typical working day.

The single entry point of the investigated ARS facility indicated that the main vehicle travel route was the corridor along the north-south axis. As a result, an "artificial" linear CO mass source was assumed, measuring $22.0 \mathrm{~m} \times 0.4 \mathrm{~m}$; it was placed in the main ARS corridor (c.f. Figure 2), at a height of $0.2 \mathrm{~m}$, which corresponded to the typical height of a vehicle's exhaust. A "transient" CO mass source was formulated, utilizing information regarding the time evolution of the average number of vehicles with operating engines in the entire ARS (c.f. Figure 4); the respective values were multiplied by the average $\mathrm{CO}$ emission rate calculated for the specific facility (c.f. Table 4). The time evolution of the "transient" CO mass source term, which was applied to the entire "artificial" linear source, is shown in Figure 5. The obtained $\mathrm{CO}$ mass flow rate profile may be applied in general engineering calculations or CFD simulations of medium-sized ARS facilities, when on-site measurements are either not available or impossible to obtain (e.g. preliminary mechanical ventilation design studies). 


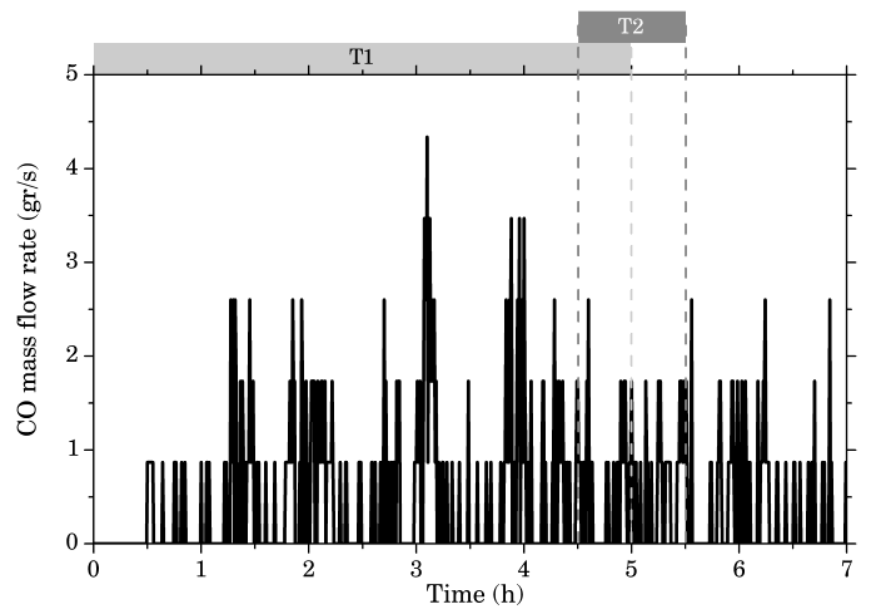

Figure 5. Time evolution of CO mass flow rate along the "artificial" linear CO source.

\section{Results and Discussion}

The FDS code was utilized to perform CFD simulations of the investigated ARS facility; the simulation time (T1) corresponds to the initial 5 hour period (from 09:00 to 14:00) of a typical working day (c.f. Figure 5). A snapshot of the developing flow-field, $160 \mathrm{~min}$ after the start of the simulation, is presented in Figure 6 (left). Predictions of the "impure" air velocity vectors are depicted at three characteristic height levels. The lower level $(0.4 \mathrm{~m})$ was located near the CO emission source, the medium level $(1.6 \mathrm{~m})$ corresponded to the average occupant breathing height and the higher level $(2.8 \mathrm{~m})$ was located near the vents of the ventilation system. Characteristics of the developing flow-field could generally be affected by the natural and mechanical ventilation openings, as well as the placement of the vehicles. The solid bodies, corresponding to the simulated vehicles, would impede the flow, thus resulting in higher absolute velocity values at the lower level $(0.4 \mathrm{~m})$; the maximum predicted value, located near the north-east corner of the facility, was equal to $1.9 \mathrm{~m} / \mathrm{s}$. It is evident that a variety of recirculation zones was developed, mainly near the north-east, north-west and south-west corners of the ARS; these were mainly induced by corner recirculation of the air stream flow due to wall confinement.

The influence of "fresh" air entrainment through the main entrance (A1) is evident. A distinctive flow, with mainly a northern direction, was developed along the main ARS corridor. This flow feature was mainly observed at the lower heights $(0.4 \mathrm{~m}, 1.6 \mathrm{~m})$; the transverse flow induced by the ventilation vents became more prominent near the ceiling $(2.8 \mathrm{~m})$. In general, the average velocity at the occupant breathing height $(1.6 \mathrm{~m})$ was 0.8 $\mathrm{m} / \mathrm{s}$, which is significantly lower than the suggested $1.5 \mathrm{~m} / \mathrm{s}$ limit, related to human comfort [28]. The mean velocity values predicted in the office area are negligible. 

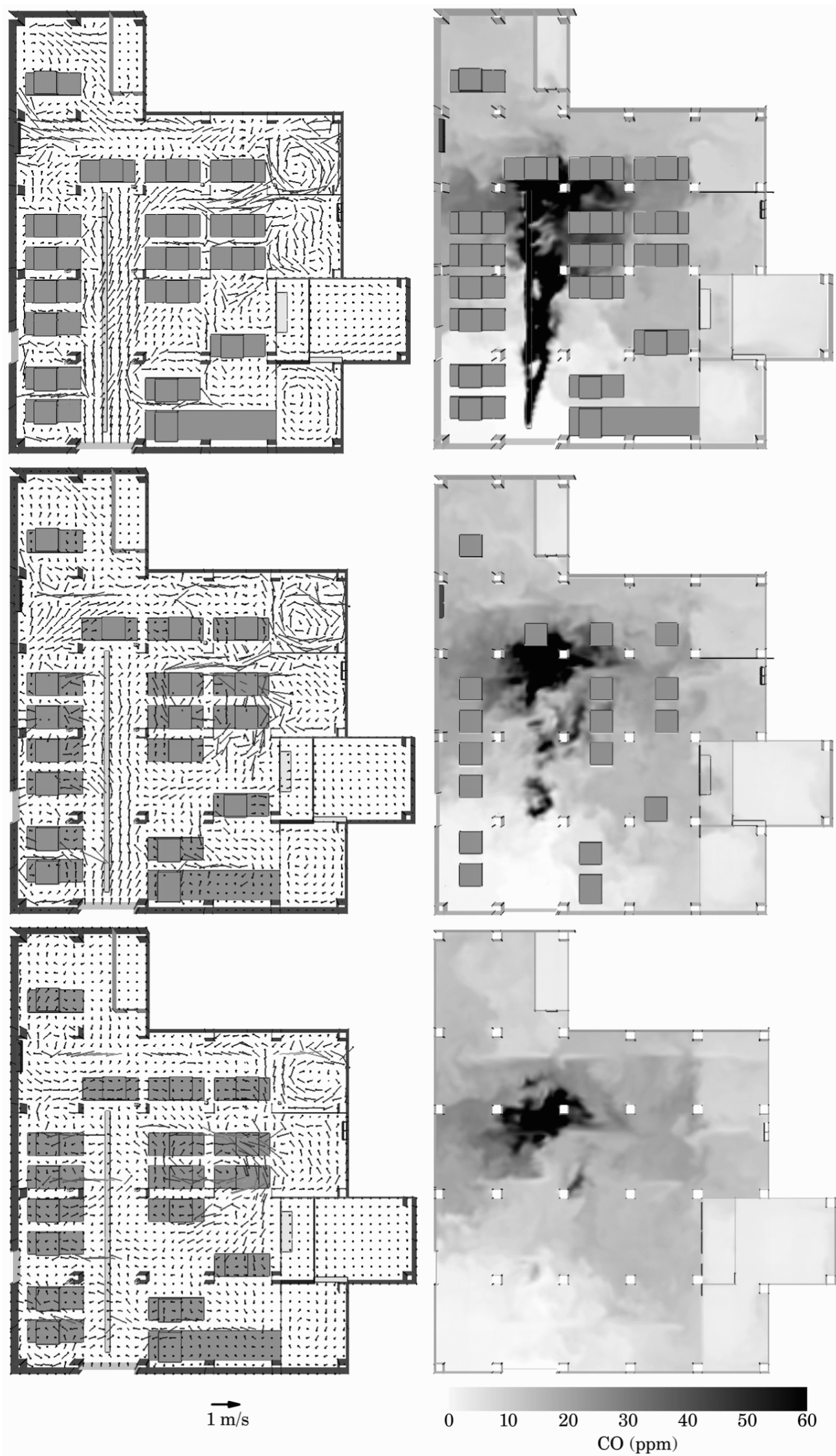

Figure 6. Predictions of gas velocity vectors (left) and CO concentration (right), $0.4 \mathrm{~m}$ (top), $1.6 \mathrm{~m}$ (middle) and $2.8 \mathrm{~m}$ (bottom) above ground level, $160 \mathrm{~min}$ after the start of the simulation. 
Predictions of $\mathrm{CO}$ concentration iso-surfaces, $160 \mathrm{~min}$ after the start of the simulation, at the same three characteristics heights $(0.4 \mathrm{~m}, 1.6 \mathrm{~m}$ and $2.8 \mathrm{~m})$ above the ground level, are shown in Figure 6 (right). In general, CO concentration levels inside the ARS facility were not uniformly distributed. As expected, higher $\mathrm{CO}$ levels were observed near the ground level $(0.4 \mathrm{~m})$, where the $\mathrm{CO}$ source was located, while lower values were predicted near the ceiling $(2.8 \mathrm{~m})$, where the ventilation vents were placed. The effect of the mean flow developing on the main corridor, associated with air entrainment through the main entrance, is evident. CO was mainly dispersed towards the northern side of the ARS facility. At the occupant breathing height $(1.6 \mathrm{~m})$, the highest calculated instantaneous CO concentrations were equal to $40 \mathrm{ppm}$. The presence of vehicles could significantly affect the developing flow characteristics at lower heights $(0.4 \mathrm{~m})$; CO concentrations became more homogeneous near the ceiling $(2.8 \mathrm{~m})$.

\section{Validation Study}

$\mathrm{CO}$ concentration predictions were validated, as shown in Figure 7, by comparing the numerical results to the respective measurements obtained in the monitoring positions M1 and M2 (c.f. Figure 1). A very good qualitative and quantitative agreement was observed in the case of monitoring position M2 (Figure 7, right). The predicted values of CO concentrations were very close to the measured values; a slight time-delay was observed after approximately $2.5 \mathrm{~h}$. Good qualitative agreement was also observed for monitoring position M1 (Figure 7, left); however, in this case, a less satisfactory quantitative agreement was achieved, since CO concentration predictions were constantly lower than the corresponding measured values.

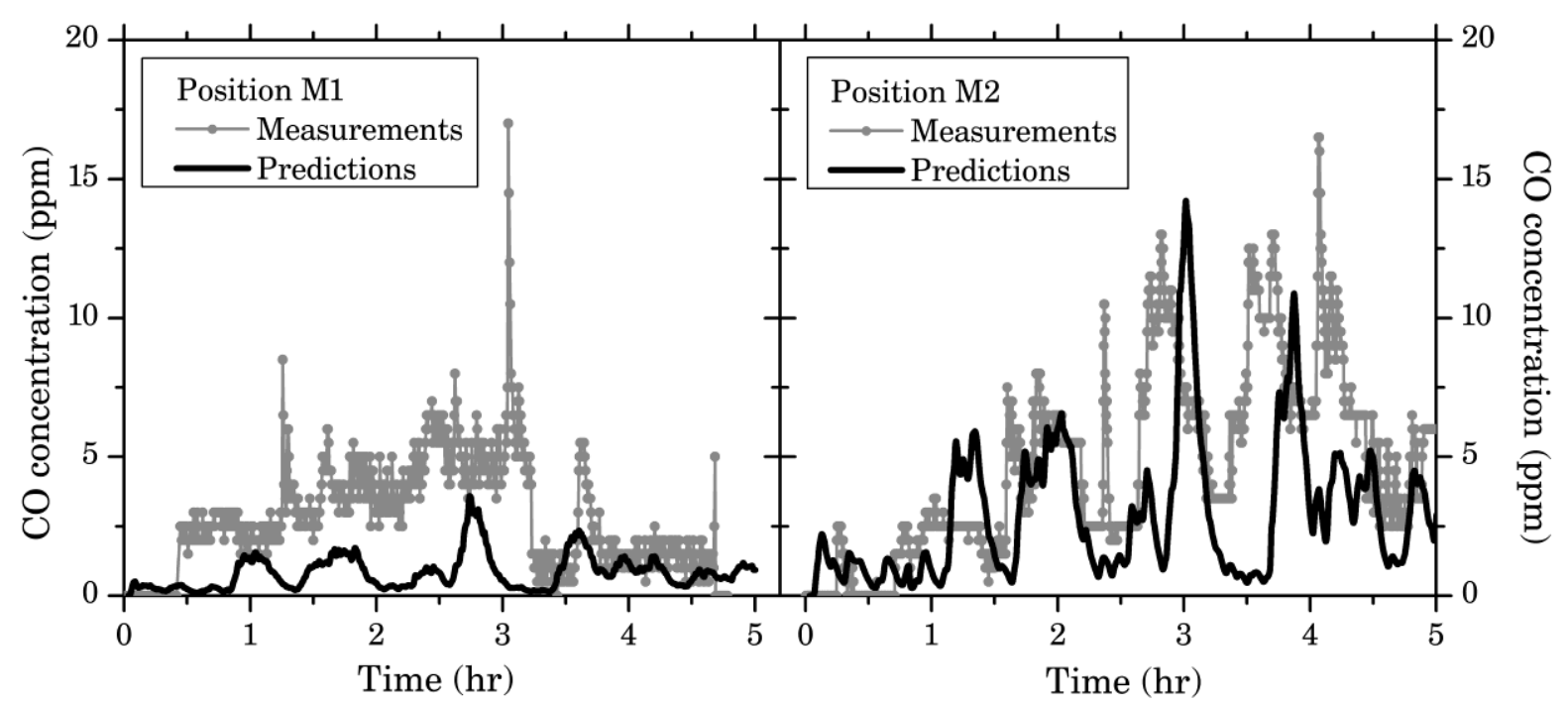

Figure 7. Comparison of $\mathrm{CO}$ concentration measurements and predictions in positions $\mathrm{M} 1$ (left) and M2 (right).

The observed discrepancies could be mainly attributed to the utilization of constant average velocity values for the description of "fresh" air entrainment through the main entrance. In reality, the measured entrainment velocities were highly fluctuating. Moreover, the utilization of a homogeneous linear $\mathrm{CO}$ mass source could have an adverse effect on the prediction quality, since the majority of vehicles with operating engines, during the measurement period, were actually located near the main entrance. The good quantitative agreement observed in the M2 monitoring position suggests that the latter was less 
affected by the aforementioned assumptions, since it was located far from the main entrance; the characteristics of the developing flow-field near the M2 position were mainly influenced by the ventilation vents.

Overall, the qualitative and quantitative agreement between the obtained numerical results and the available experimental data was quite satisfactory, despite the complexity of the developing flow-field and the simplifying assumptions employed in the simulation. Therefore, the applicability of CFD tools to effectively simulate CO dispersion in ARS facilities is confirmed. CFD simulations can be reliably used to assist the mechanical ventilation system design of such facilities.

\section{Parametric Studies}

The investigated ARS facility utilizes a continuously operating mechanical ventilation system that is set to provide "fresh" ambient air at a rate of $8 \mathrm{ACH}$, following relevant regulations. Aiming to determine the energy consumption savings potential in the mechanical ventilation system, an alternative ventilation strategy was investigated, based on the concept of the intermittent "dynamic" activation of the ventilation fans. Dynamic ventilation systems were operated in conjunction with properly installed CO sensors. In general, when $\mathrm{CO}$ readings are higher than a preset value, the ventilation system is turned on; when the measured CO concentrations drop below a specific level, the ventilation system is turned off. It is evident that, compared to the conventional continuously operating systems, dynamic ventilation systems could provide significant financial and environmental advantages, by means of energy consumption savings and reduction of relevant maintenance costs. Dynamic ventilation systems are commonly installed in automotive parking garage facilities.

The potential application of such systems in ARS facilities was investigated by means of a CFD parametric study. CFD simulations were performed for a characteristic one hour time period, between 13:30 and 14:30 (T2 in Figure 5). Three alternative test cases were considered and their main characteristics are presented in Table 5. Test Case 1 (TC1) corresponds to the conventional continuously operating ventilation system that is currently used in the ARS facility. Test Cases 2 (TC2) and 3 (TC3) refer to dynamic ventilation systems exhibiting a variable fan operation. In TC2, whenever any of the sensors detects a CO concentration level above $25 \mathrm{ppm}$ the ventilation would be turned on; when all CO sensor readings fall below $25 \mathrm{ppm}$, the ventilation would be turned off. In TC3, two ventilation "triggering" points were used; the ventilation system would be turned on when any sensor detects a $\mathrm{CO}$ concentration level above $25 \mathrm{ppm}$ and turned off when $\mathrm{CO}$ concentration readings in all sensors drop below 9 ppm. Selection of the characteristic "triggering" CO concentration level (25 ppm) was based on similar applications of dynamic ventilation systems in underground parking facilities.

Table 5. Characteristics of the investigated test cases.

\begin{tabular}{ccc}
\hline \multirow{2}{*}{ Test Case } & \multicolumn{2}{c}{ CO concentration (ppm) } \\
& “Off” Trigger & “On” Trigger \\
\hline TC1 & - & 0 \\
TC2 & $<25$ & $>25$ \\
TC3 & $<9$ & $>25$ \\
\hline
\end{tabular}


The efficiency of a dynamic ventilation system is significantly affected by the proper selection of the CO sensor positions. Since the main aim of such systems is to achieve acceptable IAQ levels in the occupant's breathing zone, CO sensors are commonly installed at the mean breathing height $(1.6 \mathrm{~m})$. According to the Greek legislation for underground parking garage facilities [29], at least $85 \%$ of the total floor area should be monitored by the installed $\mathrm{CO}$ sensors; each sensor is required to monitor a $10 \mathrm{~m}$ radius and should be located away from direct contact with the engine exhaust pipes, doorways, ventilation inlets, outlets and areas with high airflow rates. Aiming to fulfil all the aforementioned criteria, four characteristic positions (C1-C4), located at the building's supporting columns, were selected for $\mathrm{CO}$ sensor installation (Figure 8). In order to investigate the efficiency of the investigated ventilation systems, four different monitoring positions were selected (W1W4), corresponding to the typical working stations of the ARS employees (Figure 8). Position W1 was situated near the entrance of the ARS. Positions W2 and W3 corresponded to the innermost working stations, whereas position W4 represented a working station inside the office areas, which are accessible by the customers.

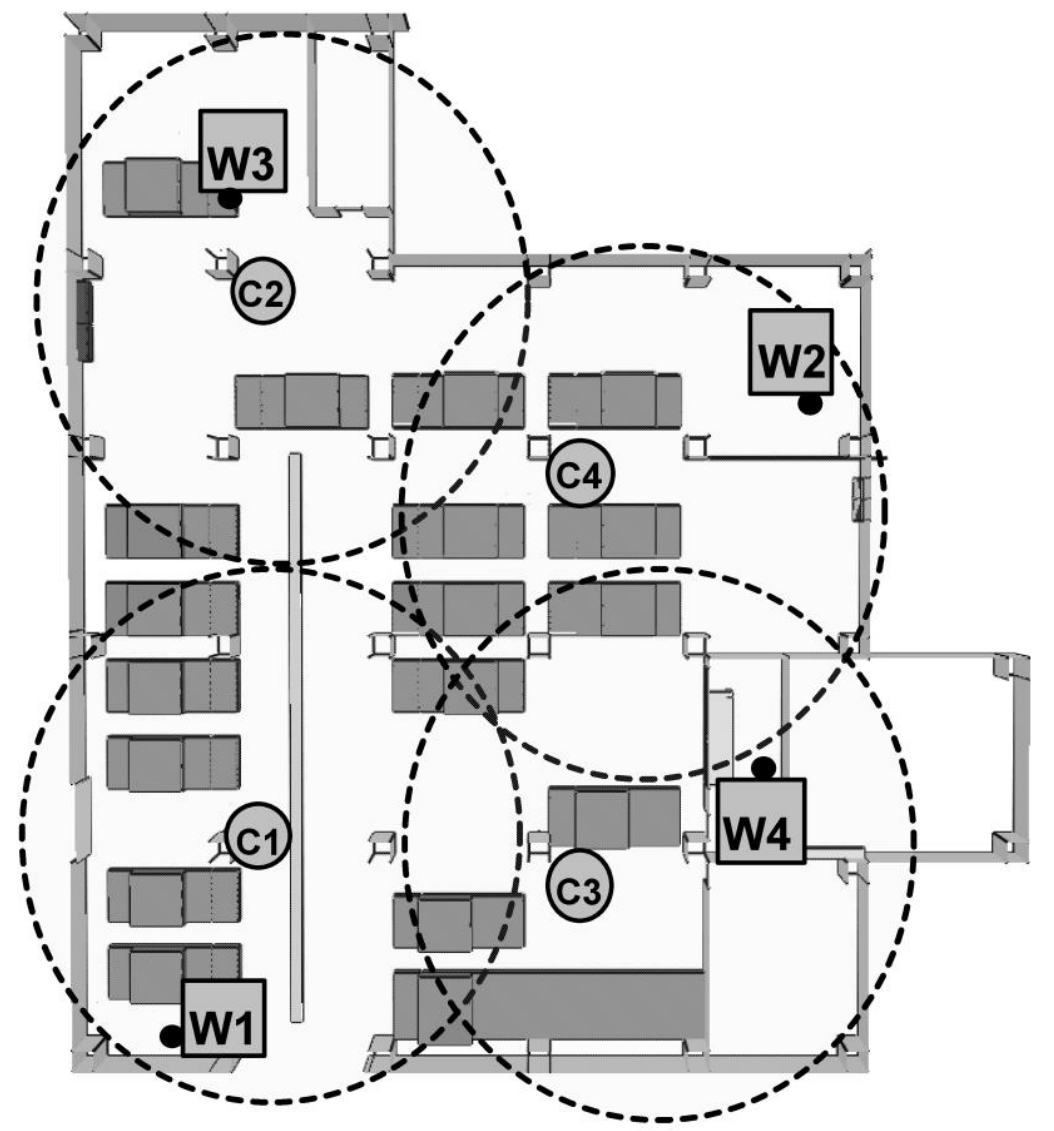

Figure 8. Layout of CO sensors (C1-C4) and monitoring locations (W1-W4) inside the ARS.

Two snapshots of the predicted "impure" air velocity vectors in the southern ARS region, $51 \mathrm{~min}$ and $58 \mathrm{~min}$ after the start of the simulation, are depicted in Figure 9, highlighting the characteristics of the developing flow-field induced by the investigated ventilation systems. In all cases, the ventilation system was operating at the 51 min mark and in both dynamic ventilation system cases (TC2, TC3), the ventilation was not operative at the 58 min mark. The continuously operating ventilation system (TC1) had resulted in a rather intense flow-field, where no areas of stagnant flow can be observed. Maximum velocity 
values of nearly $1 \mathrm{~m} / \mathrm{s}$ were observed near the supply vents. Strong transverse currents ensure sufficient dispersion of the $\mathrm{CO}$ emitted through the $\mathrm{CO}$ linear mass source. Less intensive flow conditions were observed in the dynamic ventilation system cases (TC2, TC3). Mild recirculation zones were also developed in these cases, ensuring adequate CO dispersion. Flow inertia phenomena could be observed at the 58 min mark where, despite the fact that the ventilation system was turned off, a low magnitude velocity field was still present.

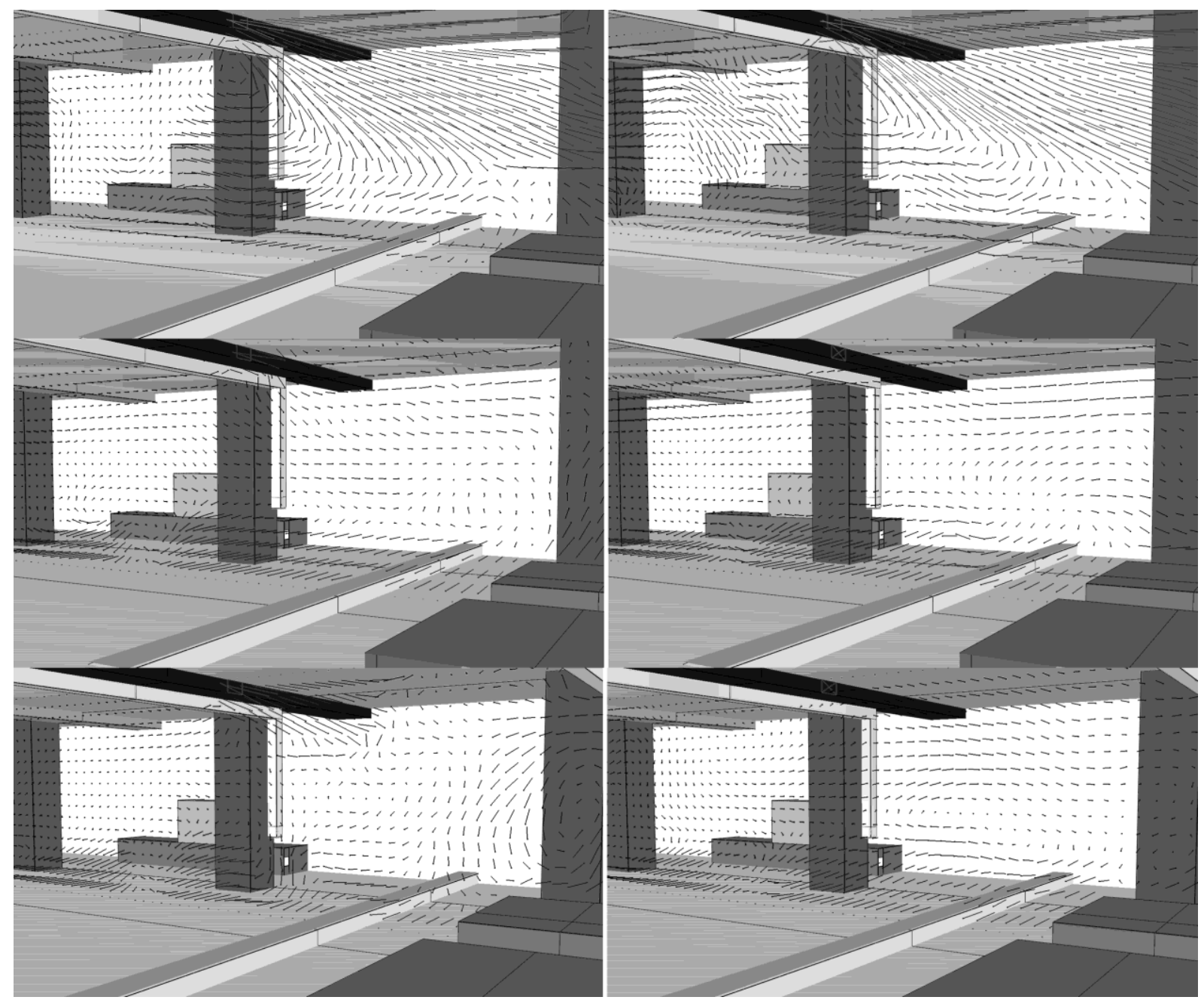

Figure 9. Predictions of the "impure" air velocity vectors for TC1 (up), TC2 (middle) and TC3 (down), $51 \mathrm{~min}$ (left) and $58 \mathrm{~min}$ (right) after the start of the simulation.

The obtained instantaneous $\mathrm{CO}$ concentration predictions for all the considered test cases are depicted in Figure 10. As expected, CO concentration levels achieved in the continuously operating ventilation system (TC1) were generally lower than the corresponding values observed in the dynamic ventilation systems (TC2, TC3). However, in all the examined test cases, the $15 \mathrm{~min}, 30 \mathrm{~min}$ and $1 \mathrm{~h}$ TWA CO concentrations did not exceed the respective guideline values as suggested by various international organizations (c.f. Table 1). As a result, both dynamic ventilation systems (TC2, TC3) are capable of effectively maintaining acceptable IAQ levels. 


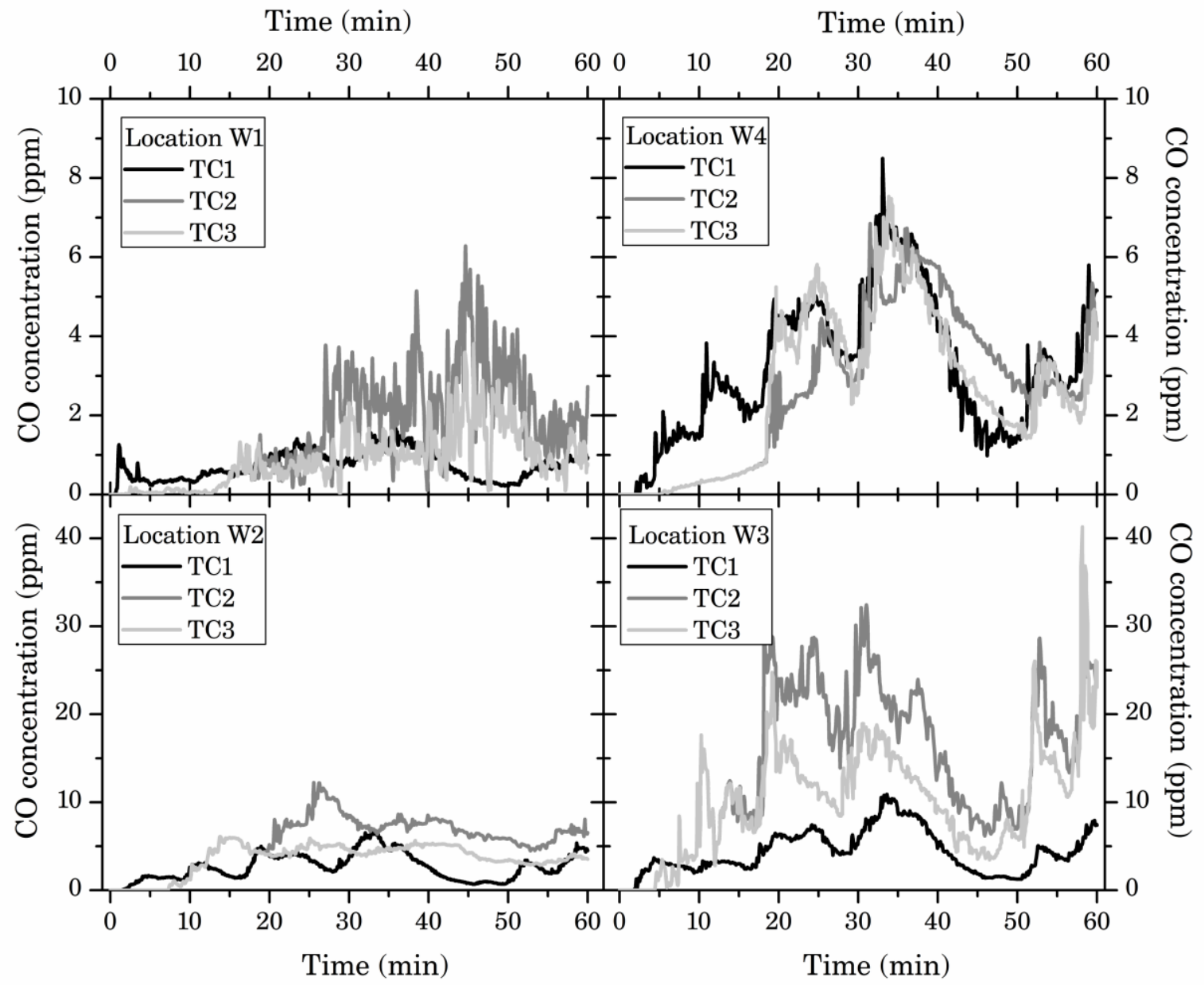

Figure 10. CO concentration predictions for the examined test cases.

Predicted values of instantaneous CO concentrations in monitoring position W3 were significantly higher than the other monitoring locations. This could be attributed to insufficient ventilation conditions prevailing in the north-west corner of the ARS facility. In general, when two different "triggering" points were used to activate and deactivate the ventilation system (TC3), the obtained $\mathrm{CO}$ concentration predictions would lie quite close to the reference case (TC1).

The activation time of the dynamic ventilation systems (TC2, TC3) for the investigated $1 \mathrm{~h}$ period is illustrated in Figure 11. The TC2 overall activation time corresponds to $13 \%$ of the total simulation time, whereas the TC3 dynamic ventilation system was operated for approximately $42 \%$ of the $1 \mathrm{~h}$ simulation period. However, the single "triggering" point utilized in TC2 results in frequent changes of the operating mode; in several cases, the ventilation fans were activated for very small time intervals (e.g. $30 \mathrm{~s}$ ). Overall, for the entire $1 \mathrm{~h}$ simulation period, there were 20 system activation events recorded for TC2, whereas only 4 were observed for TC3. Frequent switch-on and shut-down events of the ventilation fans could increase maintenance costs and decrease equipment service life [30]. As a result, despite the significant potential energy savings that can be achieved by implementing the TC2 ventilation strategy, the TC3 provides a better overall solution, corresponding to a balanced compromise between the potential energy savings, the $\mathrm{CO}$ levels and maintenance costs. 


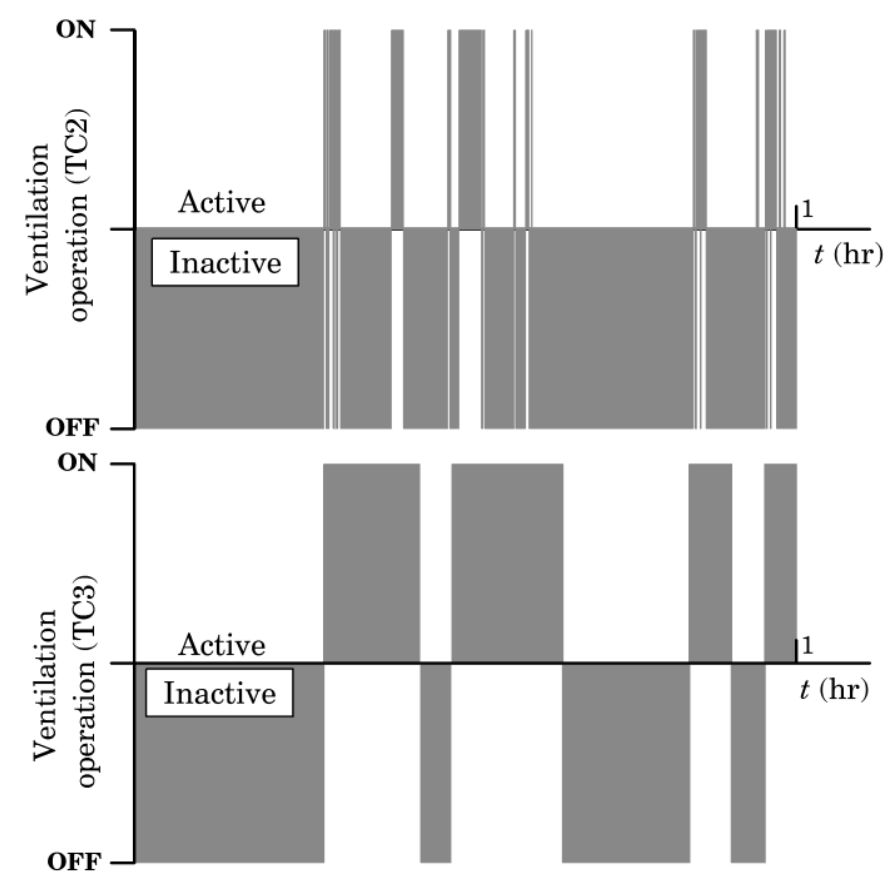

Figure 11. Activation time of the ventilation system for TC2 (up) and TC3 (down).

\section{Conclusions}

High CO concentration levels may pose a serious health hazard for occupational safety in indoor environments, especially in the case of Automotive Repair Shops (ARS), where employees are exposed on a daily basis to vehicle ICE exhaust emissions. This work focused on CO production and dispersion in ARS facilities, using both experimental investigation and numerical simulation approaches. Detailed measurements of $\mathrm{CO}$ concentrations, vehicle traffic and "impure" air velocities were performed in a medium-sized ARS. The experimental data have provided generalized quantitative information regarding $\mathrm{CO}$ emission rates in ARS facilities. The obtained temporal profiles can be used in both occupational safety engineering calculations and numerical simulations.

A detailed CFD simulation study of the investigated ARS facility was performed using the FDS code. CO concentration measurements were used to validate the numerical predictions. An overall good qualitative and quantitative agreement has been achieved. The complexity of the developing flow, in conjunction with the numerous simplifying assumptions employed in the simulations, render the obtained results acceptable for engineering purposes.

A parametric CFD study was also performed to investigate the effects of continuous and dynamic ventilation system strategies, on both IAQ levels and total energy consumption. Three test cases were considered, the first corresponding to the continuous operation of the ventilation system and the other two referring to different dynamic ventilation system strategies. The latter was based on $\mathrm{CO}$ concentration measurements provided by appropriately located CO sensors; two alternative ventilation system "triggering" points were examined.

It has been shown that significant energy consumption savings can be achieved when the dynamic ventilation approach is utilized. The ability of modern CFD tools to support the design or re-design of mechanical ventilation systems, to improve the indoor air quality for ARS employees has been demonstrated. CFD codes can provide a highly accurate and lowcost simulation tool that would enable the designer to obtain significant insight regarding 
the developing flow and concentration fields in the simulated facility, for a variety of different ventilation scenarios.

\section{References}

[1] Turns RS: An Introduction to Combustion, Concepts and Applications. 3rd ed. McGraw Hill, Singapore; 2011.

[2] Tam CW, Bevan RJ, Harrison PTC, Youngs LC and Crump D: Public Health Impacts of Exposure to Carbon Monoxide from Gas Appliances in UK Homes - Are we missing something?: Indoor Built Environ 2012; 21(2): 229-240.

[3] Nelson GL: Effects of carbon monoxide in man: Exposure fatality studies; in: Hischler MM, Debanne SM, Larsen JB, Nelson GL: Carbon monoxide and human lethality: fire and non-fire studies. Elsevier Science Publishers Ltd, London, U.K.; 1993: 3-62.

[4] Bateman DN: Carbon Monoxide: Medicine 2007; 35:604-5.

[5] Chow WK, Wong LT, Fung WY: Field study on the indoor thermal environment and carbon monoxide levels in a large underground car park: Tunn Undergr Sp Tech 1996;11:333-43.

[6] Chaloulakou A, Duci A, Spyrellis N: Exposure to carbon monoxide in enclosed multilevel parking garages in the central Athens: Indoor Built Environ 2002;11:191-201.

[7] Ho JC, Xue H, Tay KL: A field study on determination of carbon monoxide level and thermal environment in an underground car park: Build Environ 2004;39:67-75.

[8] Kim RS, Dominici F, Buckley JT: Concentrations of vehicle-related air pollutants in an urban parking garage: Environ Res 2007;105:291-9.

[9] Apte MG: A population-based exposure assessment methodology for carbon monoxide: development of a carbon monoxide passive sampler and occupational dosimeter. PH.D. Thesis, University of California, Berkeley, CA: U.S. Department of Energy, Lawrence Berkeley National Laboratory, Environmental Energy Technologies Division; 1997.

[10] Amendola AA, Hanes NB: Characterization of indoor carbon monoxide levels produced by the automobile: in Indoor Air: proceedings of the 3rd International Conference on Indoor Air Quality and Climate, Stockholm, Sweden, August 20-24, 1984: Vol. 4, pp.97-102.

[11] Flachsbart PG: Human exposure to carbon monoxide from mobile sources. Chemosphere: Global Change Science 1999;1:301-29.

[12] WHO: Air quality Guidelines. 2nd Edition, Copenhagen; Regional Office for Europe, 2000.

[13] NIOSH: The Registry of Toxic Effects of Chemical Substances, Carbon Monoxide. Cincinnati, OH: U.S. Department of Health and Human Services, Public Health Service, Centers for Disease Control, National Institute for Occupational Safety and Health, 2004.

[14] ACGIH: Thresholds limit values and biological exposure indices 1992-1993. Cincinnati: American Conference of Governmental Industrial Hygienists; 1994.

[15] Council Directive 96/62/EC of 27 September 1996: Ambient Air Quality Assessment and Management: Official Journal of the European Community L 296 1996; 55-63.

[16] Chaloulakou A, Mavroidis I, Duci A: Indoor and outdoor carbon monoxide concentration relationships at different micro environments in the Athens area: Chemosphere 2003;52:1007-19.

[17] Bari S, Naser J: Simulation of smoke from a burning vehicle and pollution levels caused by traffic jam in a road tunnel: Tunn Undergr Sp Tech 2005;20:281-90.

[18] Lin Z, Jiang F, Chow TT, Tsang CF, Lu WZZ: CFD analysis of ventilation effectiveness in a public transport interchange: Build Environ 2006;41:254-61. 
[19] Chan MY, Chow WK: Car-park ventilation system: performance evaluation: Build Environ 2004;39:635-43.

[20] Chow WK: On ventilation design for underground car parks: Tunn Undergr Sp Tech 1995; 10:225-45.

[21] Greek Presidential Decree: No. 78/1988 governing the terms and conditions for establishing and operating repair shops for automobiles, motorcycles and motorbikes: Greek Off. Gaz. 34/A/25-2-1988 (in Greek).

[22] McGrattan K, Hostikka S, Floyd J, Baum H, Rehm R, Mell W, McDermott R: Fire Dynamics Simulator (Version 5) Technical Reference Guide. 1018-5. NIST Special Publication; 2010.

[23] Rinne T, Hietaniemi J, Hostikka S: Experimental validation of the FDS simulations of smoke and toxic gas concentrations. VTT Working Papers 66, VTT-WORK-66, ISBN 978951-38-6617-4.

[24] Mniszewski KR, Pape R: The Use of FDS for Estimation of Flammable Gas/Vapor Concentrations. in Proceedings of $3^{\text {rd }}$ Technical Symposium on Computer Applications in Fire Protection Engineering, Society of Fire Protection Engineers, Blatimore, U.S.A., 1213 September 2001.

[25] Musser A, Mac Grattan K, Palmer J: Evaluation of a Fast, Simplified Computational Fluid Dynamics Model for Solving Room Airflow Problems. NISTIR 6760; 2001.

[26] ASHRAE: ASHRAE Handbook-HVAC applications. American Society of Heating, Refrigerating and Air-Conditioning Engineers Inc, Atlanta, GA, U.S.A., Chapter 12; 15.

[27] Papakonstantinou K, Chaloulakou A, Duci A, Vlachakis N and Markatos N: Air quality in an underground garage: computational and experimental investigation of ventilation effectiveness: Energy and Buildings 2003;35: 933-40.

[28] Spengler JD, Chen QY, Dilwali KM: Indoor Air quality factors in designing a healthy building; In: Spengler JD, Samet JM, McCarthy JF, editors: Indoor Air Quality Handbook. New York: McGraw-Hill; 2000: 5.1-5.30.

[29] Greek Presidential Decree: No. 455/76 governing the terms and conditions for establishing and operating car stations and installing in them car-washes and lubricating devices. Greek Off. Gaz. 169/A/5-7-1976 (in Greek).

[30] Burgess WA, Ellenbecker MJ, Treitman RD: Ventilation for control of the work environment. $2^{\text {nd }}$ Edition, John Wiley and Sons, New Jersey, U.S.A., 2004. 